\begin{tabular}{|c|l|}
\hline Title & Isolation of a thermotolerant bacterium producing medium-chain-length poly hy droxyalkanoate \\
\hline Author(s) & $\begin{array}{l}\text { Satoh, Y asuharu; Tajima, Kenji; Nakamoto, Sho; X uerong, Han; Matsushima, Tokuo; Ohshima, Takeshi; Kawano, } \\
\text { Shin; Erata, Tomoki; Dairi, Tohru; Munekata, Masanobu }\end{array}$ \\
\hline Citation & $\begin{array}{l}\text { Journal of A pplied Microbiology, 1111(4), 811-817 } \\
\text { https://doi.org/10.1111/.1365-2672.2011.05093.x }\end{array}$ \\
\hline Issue Date & 2011-10 \\
\hline Doc URL & http://hdl.handle.net/2115/50148 \\
\hline Rights & The definitive version is avail lable at www.blackwell-synergy.com \\
\hline Type & article (author version) \\
\hline File Information & JAM111-4_811-817.pdf \\
\hline
\end{tabular}

Instructions for use 


\section{Isolation of a Thermotolerant Bacterium Producing Medium-chain-length Polyhydroxyalkanoate}

Yasuharu Satoh ${ }^{1 *}$, Kenji Tajima ${ }^{1}$, Sho Nakamoto ${ }^{1}$, Han Xuerong ${ }^{1}$, Tokuo Matsushima ${ }^{2}$,

Takeshi Ohshima $^{3}$, Shin Kawano ${ }^{4}$, Tomoki Erata ${ }^{1}$, Tohru Dairi ${ }^{1 *}$, Masanobu Munekata ${ }^{1}$

${ }^{1}$ Division of Biotechnology and Macromolecular Chemistry, Graduate School of Engineering, Hokkaido University, Sapporo, Japan

${ }^{2}$ Agri Bio Industry Inc., Sapporo, Japan

${ }^{3}$ Hokusei Kigyou Co., Ltd, Sapporo, Japan

${ }^{4}$ Database Center for Life Science (DBCLS), Tokyo, Japan

${ }^{*}$ Corresponding authors:

Address: Hokkaido University, N13-W8, Kita-ku, Sapporo 060-8628, Japan

E-mail: syasu@eng.hokudai.ac.jp, dairi@eng.hokudai.ac.jp

Tel \& Fax: +81-11-706-7118

Running headline: Thermotolerant bacterium producing PHA

Keywords: Polyhydroxyalkanoate, Thermotolerant bacterium, Pseudomonas, Biodiesel fuel by-product 


\section{ABSTRACT}

Aims: The aim of the present study was to isolate a thermotolerant microorganism that produces polyhydroxyalkanoates (PHAs) composed of medium-chain-length (mcl)-HA units from a biodiesel fuel (BDF) by-product as a carbon source.

Methods and Results: We successfully isolated a thermotolerant microorganism, strain SG4502, capable to accumulate mcl-PHA from a BDF by-product as a carbon source at a cultivation temperature of $45^{\circ} \mathrm{C}$. The strain could also produce mcl-PHA from acetate, octanoate, and dodecanoate as sole carbon sources at cultivation temperatures up to $55^{\circ} \mathrm{C}$. Taxonomic studies and 16S rRNA gene sequence analysis revealed that strain SG4502 was phylogenetically affiliated with species of the genus Pseudomonas. This study is the first report of PHA synthesis by a thermotolerant Pseudomonas.

Conclusions: A novel thermotolerant bacterium capable to accumulate mcl-PHA from a BDF by-product was successfully isolated.

Significance and Impact of the Study: A major issue regarding industrial production of microbial PHAs is their much higher production cost compared with conventional petrochemical-based plastic materials. Especially significant are the cost of a fermentative substrate and the running cost to maintain a temperature suitable for microbial growth. Thus, strain SG4502, isolated in this study, which assimilates BDF by-product and produces PHA at high temperature, would be very useful for practical application in industry. 


\section{INTRODUCTION}

Polyhydroxyalkanoates (PHAs), which originate from renewable resources such as sugars and vegetable oils, have attracted great interest as alternatives to petrochemical-based plastics because of the similarity of their material properties to various thermoplastics and elastomers and their complete biodegradability (Sudesh et al. 2000; Chen 2009). PHAs comprise a large class of polyesters that are accumulated as carbon and energy storage material by a wide variety of bacteria. PHAs are commonly grouped into two major categories according to the number of carbon atoms in their monomeric units, which are short-chain-length (scl)-PHAs with C3 to C5 monomer units and medium-chain-length (mcl)-PHAs with C6 to C14 monomer units. The scl-PHAs are generally more crystalline than the mcl-PHAs and usually exhibit thermoplastic-like properties. In contrast, the mcl-PHAs exhibit elastomer- or adhesive-like properties depending on the specific side-chain length and the degree of unsaturation.

However, a major issue regarding industrial production of microbial PHAs is their much higher production cost compared with conventional petrochemical-based plastic materials. For industrial microbial production of PHAs, the cost of the fermentative substrate constitutes a significant proportion of the total costs (Lee and Choi 1998; Chen 2009). Production of biopolymers using inexpensive biomass and carbon sources available in by-products or waste streams potentially decreases the production cost and also helps to convert these materials into value-added products. Accordingly, research efforts abound to exploit inexpensive 
fermentable raw materials as fermentative substrates for PHA production.

Another concern in the application of microbial PHAs to industrial production is the running cost of maintaining a temperature suitable for microbial growth (Fischer et al. 2008). In addition to the influence of external temperature increases, fermentation broths also heat up due to exothermic metabolic reactions. In many warm countries, summer temperatures are frequently $>40^{\circ} \mathrm{C}$ and the fermentation vessel's temperature would be over $40^{\circ} \mathrm{C}$ in the absence of a cooling system. This overheating problem is partially overcome by spraying cold water on the fermentation vessel walls, but this increases the production cost. Moreover, an advantage of processing at higher temperatures is that it significantly reduces the chance of contamination. Thermophilic or thermotolerant microbial cells thus offer the advantage of enabling operation at elevated temperatures in industrial fermentation. It has been reported that the thermophilic bacterium Thermus thermophilus HB8 is a PHA producer (Pantazaki et al. 2003). This bacterium accumulated PHA composed of $\mathrm{C} 4$ to $\mathrm{C} 12$ monomer units at a cultivation temperature of $75^{\circ} \mathrm{C}$. However, the optimal temperature range, $65-72^{\circ} \mathrm{C}$, and the minimum temperature, $47^{\circ} \mathrm{C}$ (Oshima and Imahori 1974), are too high for industrial fermentation, because the need to maintain such high cultivation temperatures requires the expense of extra energy.

To overcome these issues, in this study we attempted to screen thermotolerant bacteria capable of producing PHAs from biodiesel fuel (BDF) by-products whose main component is glycerol (Yazdani and Gonzalez 2007; Sivakumar et al. 2010). BDF, an environmentally 
friendly and sustainable alternative to fossil fuels, is derived from vegetable oils, fats and waste edible oils via a methyl-esterification process. BDF production on a large commercial scale has led to the accumulation of BDF by-product. Although BDF by-product was thought to be unfit for the growth and fermentation of some microorganisms, owing to its considerable amounts of certain impurities, such as soap, methanol and free fatty acids (Yazdani and Gonzalez 2007), we attempted to apply it to PHA production. As a result, we succeeded in isolating one microorganism, designated SG4502, which is thermotolerant and can produce mcl-PHA from BDF by-product as a sole carbon source at cultivation temperatures up to $55^{\circ} \mathrm{C}$.

\section{MATERIALS AND METHODS}

\section{Media}

Mineral salt (MS) medium, containing $9.0 \mathrm{~g}$ of $\mathrm{Na}_{2} \mathrm{HPO}_{4} 12 \mathrm{H}_{2} \mathrm{O}, 1.5 \mathrm{~g}$ of $\mathrm{KH}_{2} \mathrm{PO}_{4}, 0.1$ $\mathrm{g}$ of $\mathrm{NH}_{4} \mathrm{Cl}, 0.2 \mathrm{~g}$ of $\mathrm{MgSO}_{4} 7 \mathrm{H}_{2} \mathrm{O}$ and $1 \mathrm{ml}$ of trace element solution per liter of distilled water (Kato et al. 1996), was used for the screening. Kato et al. also reported that higher C/N ratio promoted PHA accumulation in Pseudomonas sp. Therefore, $\mathrm{NH}_{4} \mathrm{Cl}$ was decreased to $0.05 \mathrm{~g} \mathrm{l}^{-1}$ for PHA production. Nutrient-rich (NR) medium containing $10 \mathrm{~g}$ of peptone, $2 \mathrm{~g}$ of yeast extract and $10 \mathrm{~g}$ of meat extract per liter of distilled water was used for the cultivation of bacteria. For growth on plates, NR medium with $1.5 \%$ (w/v) agar was used.

The BDF by-product used in this study was obtained from Hokusei Kigyou Co. Ltd. 
(Sapporo, Japan). The by-product contained $41.5 \%$ glycerol, $12.4 \%$ methanol and $21.4 \%$ ether-soluble materials such as fatty acid methyl ester. This was neutralized by $\mathrm{H}_{2} \mathrm{SO}_{4}$ before used.

\section{Isolation of bacteria accumulating PHA}

Samples, which were collected from sewage sedimentations and surface of an apparatus for producing BDF, were used as sources for the isolation of thermotolerant PHA producing bacteria. Each sample was put into $10 \mathrm{ml}$ of sterilized water and mixed. After centrifugation at $1000 \times g$ for $3 \mathrm{~min}$, each of the supernatants $(0.2 \mathrm{ml})$ was added into $50 \mathrm{ml}$ of MS medium containing $1 \%(\mathrm{w} / \mathrm{v}) \mathrm{BDF}$ by-product and incubated for $3 \mathrm{~d}$ at $45^{\circ} \mathrm{C}$ with shaking at $160 \mathrm{rpm}$. After repeating subcultures, each culture was streaked on NR agar medium and incubated at $45^{\circ} \mathrm{C}$ for $3 \mathrm{~d}$. The isolated strains were tested for PHA synthesis activity as the following: the cells were cultured in $5 \mathrm{ml}$ of NR medium at $45^{\circ} \mathrm{C}$ for $16 \mathrm{~h}$. They were inoculated in $100 \mathrm{ml}$ of nitrogen-limited MS medium containing 1\% (w/v) BDF by-product in 500-ml Erlenmeyer flasks with baffles and incubated at $45^{\circ} \mathrm{C}$ for $48 \mathrm{~h}$ with shaking at $160 \mathrm{rpm}$. The collected cells were washed with distilled water, followed by ethanol and distilled water again and then lyophilized. The dried microbial cells were subjected to gas chromatography (GC) analysis as described below.

\section{PHA production}


SG4502 was cultured in $60 \mathrm{ml}$ of NR medium at $45^{\circ} \mathrm{C}$ for $16 \mathrm{~h}$. The cultures were inoculated into 1.21 of nitrogen-limited MS medium containing a carbon source in 3-1 Erlenmeyer flasks with baffles, and incubated at 45 or $55^{\circ} \mathrm{C}$ with shaking at $130 \mathrm{rpm}$ for $48 \mathrm{~h}$. To this medium, BDF by-product was fed twice at the concentrations of $1 \%(\mathrm{w} / \mathrm{v})$ at 0 and 24 $\mathrm{h}$, respectively, during the course of cultivation. Glycerol or acetate was fed four times at the concentrations of $1,2,3$ and $4 \%(\mathrm{w} / \mathrm{v})$ at $0,12,24$ and $36 \mathrm{~h}$, respectively, during the course of cultivation. Octanoate, dodecanoate or soybean oil was added four times at the concentrations of $0.1 \%(\mathrm{w} / \mathrm{v})$ at $0,12,24$ and $36 \mathrm{~h}$, respectively, during the course of cultivation. The collected cells were washed with distilled water followed by ethanol and distilled water again and then lyophilized. Polymer was extracted from each dry microbial cell body by a Soxhlet extractor with chloroform as a solvent and then dried under reduced pressure after the solvent was removed by an evaporator.

\section{Analyses}

The sequence of 16S rDNA was analyzed with MicroSeq Full Gene 16S rDNA PCR and Sequencing kits and by the ABI PRISM 3100 genetic analyzer (Applied Biosystems Japan Ltd., Tokyo, Japan).

Polymer composition and accumulation were analyzed by the GC-2010 capillary gas chromatography system (Shimadzu Co., Kyoto, Japan) equipped with a flame ionization detector and a Zebron ZB-1 GC capillary column (0.25 mm I.D. × 30 m; Phenomenex Inc., 
CA, USA). A sample was prepared as follows: approximately $10 \mathrm{mg}$ of polymer or $50 \mathrm{mg}$ of dried microbial cell was treated with a solution containing $1.7 \mathrm{ml}$ of methanol, $0.3 \mathrm{ml}$ of sulfuric acid and $2.0 \mathrm{ml}$ of chloroform at $100^{\circ} \mathrm{C}$ for $140 \mathrm{~min}$ to convert the constituents to their methyl esters. One milliliter of water was added to the reaction mixture, and then the lower chloroform layer was used for GC analysis.

The ${ }^{1} \mathrm{H}-\mathrm{NMR}$ spectra of the polymers were obtained in deuterated chloroform $\left(\mathrm{CDCl}_{3}\right)$ using a Bruker MSL400 spectrometer $(400 \mathrm{MHz})$ at a $90^{\circ}$ pulse with a $4 \mathrm{~ms}, 3,000 \mathrm{~Hz}$ spectral width and a $4 \mathrm{~s}$ repetition rate. The chemical shifts were reported in ppm with tetramethylsilane as the internal reference.

The molecular weights of the obtained polymers were determined by using a gel-permeation chromatography (GPC) system (Shimadzu) equipped with tandem TSKgel Super HZM-H columns (6.0 mm I.D. × $150 \mathrm{~mm}$; Tosoh Co., Tokyo, Japan $)$ at $40^{\circ} \mathrm{C}$. Chloroform was used as an eluate, and the calibration was performed using polystyrene samples as standards.

\section{RESULTS}

\section{Phenotypic and phylogenetic characterization}

To obtain thermotolerant bacteria capable of accumulating PHA in a chemically defined medium containing a BDF by-product as a sole carbon source, we first carried out enrichment culture with MS medium containing a BDF by-product at a cultivation temperature of $45^{\circ} \mathrm{C}$. 
The tens of colonies isolated on NR agar medium were evaluated for their ability to produce PHA from a BDF by-product as a carbon source. The nitrogen source, $\mathrm{NH}_{4} \mathrm{Cl}$, in $\mathrm{MS}$ medium was decreased to promote PHA accumulation. The PHA accumulated in the cells was determined by GC analysis. We successfully found a strain that could produce mcl-PHA at a cultivation temperature of $45^{\circ} \mathrm{C}$. The strain was designated SG4502.

The microbiological properties of strain SG4502 were analyzed. SG4502 is an aerobic, Gram-negative, polar flagellate bacillus. The strain was able to grow up to a cultivation temperature of $55^{\circ} \mathrm{C}$, and not at $60^{\circ} \mathrm{C}$ (Figure 1). We found the strain positive for catalase, oxidase and arginine dihydrolase activities and negative for urease activity. Nitrate was not reduced. The strain grew at $\mathrm{pH} 6-10$. Growth was observed at $37-50^{\circ} \mathrm{C}$ in the presence of $4 \%$ $\mathrm{NaCl}$. Anaerobic growth did not occur in the presence of nitrate. Tweens 20 and 80 were hydrolyzed, but aesculin, gelatin, starch and skimmed milk were not. Furthermore, strain SG4502 assimilated citrate, pyruvate, succinate, malate, acetate, propionate, octanoate, decanoate, betain, L-lysine, L-asparagine, L-serin, L-glutamine, L-alanine, L-isoleucine, L-proline, dodecane, tridecane, hexadecane, nonadecane, eicosane, palmitic acid, octanal, 1-octanol, 1-dodecanol, and benzoate, but not fructose, D-mannose, D-trehalose, D-cellobiose, L-arabinose, D-glucose, L-sorbose, D-sucrose, D-xylose, D-maltose, D-mannitol, gluconate, phenylacetate, adipate, glycerol, glycine, L-cystein, L-phenylalanine, L-histidine, L-arginine, $\mathrm{N}$-acetylglucosamine, decane, SDS, salicylate, naphthalene, anthracene or phenanthrene. 
deposited in DNA Data Bank of Japan (DDBJ) sequence database under accession number AB616678. The 16S rRNA gene sequence analysis using the BLAST program (http://blast.ncbi.nlm.nih.gov/Blast.cgi) indicated that strain SG4502 belongs to the genus Pseudomonas and that the closest phylogenetic neighbors of the strain are $P$. thermotolerans (99\% identity; accession number AJ311980) (Manaia and Moore 2002). Phylogenetic analyses using Molecular Evolutionary Genetics Analysis (MEGA) software version 4.0 (Tamura et al. 2007, Figure 2) show that strain SG4502 and P. thermotolerans are clustered and are relatively distant from the most closely related other Pseudomonas species.

\section{PHA productivity}

To investigate the PHA productivity of strain SG4502 at a cultivation temperature of $45^{\circ} \mathrm{C}$, the strain was cultivated under nitrogen-limiting conditions in MS medium supplemented with several types of carbon sources. Polymers accumulated in the cells were extracted from the dried cells with chloroform and then analyzed. BDF by-product was first tested as a sole carbon source. As shown in Table 1, strain SG4502 reached a total biomass (cell components plus PHA) of $1.50 \mathrm{~g} \mathrm{l}^{-1}$ for $48 \mathrm{~h}$ and accumulated $0.61 \mathrm{~g} \mathrm{l}^{-1}$ of PHA (40.6\% [w/w] of total biomass). The number-average molecular weight $(\mathrm{Mn})$ and polydispersity $(\mathrm{Mw} / \mathrm{Mn})$ of the product were determined to be $36 \times 10^{3}$ and 1.95 , respectively (Table 2$)$. The ${ }^{1} \mathrm{H}$ NMR analysis clearly indicated that the product was PHA (Figure 3). Based on GC analysis, PHA was calculated to be composed of $0.8 \mathrm{~mol} \% 3$-hydroxybutyrate (3HB, C4), 5.7 
mol\% 3-hydroxyhexanoate (3HHx, C6), 25.1 mol\% 3-hydroxyoctanoate (3HO, C8) 59.8 mol\% 3-hydroxydecanoate (3HD, C10) and 8.6 mol\% 3- hydroxydodecanoate (3HDD, C12) units.

We also used glycerol, a main component in BDF by-product, as a sole carbon source, although the assimilation test for glycerol was negative as described above. Under the polymer production conditions employed, however, the strain showed weak growth and accumulated trace amounts of polymer composed of a 3HD unit (Table 1).

Vegetable oils such as soybean oil, which have been used as feedstocks for PHA production (Kahar et al. 2004), were also examined as possible sole carbon sources. As shown in Table 1, however, strain SG4502 was unable to assimilate soybean oil under the cultivation conditions, suggesting that the strain would have no lipases to be secreted into the medium, because fatty acids were assimilated as described below.

We next compared properties of the PHA produced by strain SG4502 with those produced by P. putida and P. oleovolance (Gross et al. 1989; Huisman et al. 1989), both of which are typical mcl-PHA producers, with acetate $(\mathrm{C} 2)$, octanoate $(\mathrm{C} 8)$, and dodecanoate (C12) as sole carbon sources. Strain SG4502 produced PHA having 3HD units as a major component $(84.4 \mathrm{~mol} \%)$ with acetate as a sole carbon source. In this case, the substrates for polymer syntheses would be supplied from de novo fatty acid biosynthesis pathway (Rehm et al. 1998). When octanoate was added to MS medium as a sole carbon source, the total biomass of strain SG4502 was highest among all cultivation conditions and the $3 \mathrm{HO}$ (C8) 
content in PHA was drastically increased $(82.5 \mathrm{~mol} \%)$ (Table 1$)$. When dodecanoate (C12) was used as the sole carbon source, almost equal amounts $(40 \mathrm{~mol} \%)$ of $3 \mathrm{HD}(\mathrm{C} 10)$ and $3 \mathrm{HO}$ (C8), which would be formed respectively by one and two cycles of $\beta$-oxidation of dodecanoate, were incorporated. These results suggested that fatty acids fed in the culture broth would be efficiently incorporated into PHA. In all cases with acetate, octanoate or dodecanoate as the sole carbon source, the $\mathrm{Mn}$ and $\mathrm{Mw} / \mathrm{Mn}$ were between 7 to $11 \times 10^{4}$ and 2.0 to 2.5 , respectively. All these properties were in good agreement with those of $P$. putida and $P$. oleovolance.

The effects of cultivation temperature on cell growth, PHA productivity, and monomer composition were examined with dodecanoate as a sole carbon source at $55^{\circ} \mathrm{C}$, since strain SG4502 was able to grow at $55^{\circ} \mathrm{C}$ in NR medium and the solubility of dodecanoate increased as temperature increased (McBain and Sierichs 1948). Under the cultivation condition, the strain grew and accumulated a polymer. As for the monomer composition in the PHA, it was almost the same as that produced at $45^{\circ} \mathrm{C}$. We thus demonstrated that strain SG4502 had the ability to produce mcl-PHA at a cultivation temperature of $55^{\circ} \mathrm{C}$.

\section{DISCUSSION}

We successfully isolated a thermotolerant bacterium, strain SG4502, capable to accumulate PHA from a BDF by-product as a carbon source at temperatures up to $55^{\circ} \mathrm{C}$. Taxonomic studies and 16S rRNA gene sequence analysis revealed that strain SG4502 was 
phylogenetically affiliated with species of the genus Pseudomonas. The closest species is $P$. thermotolerans (Manaia and Moore 2002), whose PHA productivity has not been reported. Moreover, the results of assimilation tests for citrate, pyruvate, succinate, L-lysine, L-arginine, SDS and benzoate were different from each other. As a result, strain SG4502 was concluded to be a Pseudomonas sp.

The BDF by-product used in this study contained glycerol as the major component and fatty acid methyl ester as the minor component. Based on the results of cell growth and the properties of the produced PHA with BDF by-product, glycerol and fatty acids, strain SG4502 preferentially assimilated minor components rather than glycerol in the BDF by-product. However, strain SG4502 produced a trace amount of homopolymer composed of 3HD when glycerol was used as a sole carbon source, suggesting that the strain was able to utilize glycerol for PHA accumulation perhaps via de novo fatty acid biosynthesis (Rehm et al. 1998).

The PHA produced from BDF by-product has a lower molecular weight than PHAs produced from acetate, octanoate and dodecanoate under the same cultivation conditions (Table 2). Previously, the same phenomenon was reported: Ralstonia eutropha produced PHA with a lower molecular weight when cultured with glycerol as a carbon source (Madden et al. 1999). In this study, it was shown that glycerol functions as a termination reagent during a chain transfer/elongation in PHA biosynthesis, resulting in decreased molecular weight of the polymer produced. This was also the case with strain SG4502. 
To date, T. thermophilus HB8 is the only heat-tolerant bacterium producing PHA (Oshima and Imahori 1974; Pantazaki et al. 2003). However, T. thermophilus requires a cultivation temperature above $47^{\circ} \mathrm{C}$, which in turn requires more energy to maintain. As shown in this study, we have succeeded in isolating a PHA-producing strain capable of producing mcl-PHA at cultivation temperatures up to $55^{\circ} \mathrm{C}$. Although strain SG4502 would be more useful for practical application in industry, the strain did not efficiently assimilate BDF by-products, including glycerol. However, this could be overcome by the construction of a genetically engineered strain to reinforce the glycerol assimilation pathway. Previously, Solaiman et al. succeeded in conferring the assimilation capacity of oils to $P$. putida and $P$. oleovorans, which were impossible to grow on vegetable oils and fats, by introducing a gene encoding lipase; these strains produced PHA from oils (Solaiman et al. 2001). Application of the same strategy to strain SG4502 would enable the construction of an engineered strain with a high ability to assimilate BDF by-product.

\section{ACKNOWLEDGMENTS}

The authors are grateful to Mr. Eiji Yamada, Hokkaido University, for his technical assistance with NMR measurements. We also thank Mr. Yusuke Soeda, Ms. Reiko Yamato and Mr. Tetsuya Toriyabe, Agri Bio Industry Inc., for their technical support. This work was supported by the Global COE Program (Project No. B01: Catalysis as the Basis for Innovation in Materials Science) from the Ministry of Education, Culture, Sports, Science, 
and Technology, Japan; and by the Northern Advancement Center for Science \& Technology (NOASTEC).

\section{REFERENCES}

Chen, G.Q. (2009) A microbial polyhydroxyalkanoates (PHA) based bio- and materials industry. Chem Soc Rev 38, 2434-2446.

Fischer, C.R., Klein-Marcuschamer, D. and Stephanopoulos, G. (2008) Selection and optimization of microbial hosts for biofuels production. Metab Eng 10, 295-304.

Gross, R.A., DeMello, C., Lenz, R.W., Brandl, H. and Fuller, R.C. (1989) Biosynthesis and characterization of poly( $\beta$-hydroxyalkanoates) produced by Pseudomonas oleovorans. Macromolecules 22, 1106-1115.

Huisman, G.W., de Leeuw, O., Eggink, G. and Witholt, B. (1989) Synthesis of poly-3-hydroxyalkanoates is a common feature of fluorescent Pseudomonads. Appl Environ Microbiol 55, 1949-1954.

Kahar, P., Tsuge, T., Taguchi, K. and Doi, Y. (2004) High yield production of polyhydroxyalkanoates from soybean oil by Ralstonia eutropha and its recombinant strain. Polym Degrad Stab 83, 79-86.

Kato, M., Bao, H.J., Kang, C.K., Fukui, T. and Doi, Y. (1996) Production of a novel copolyester of 3-hydroxybutyric acid and medium chain length 3-hydroxyalkanaic acids by Pseudomonas sp. 61-3 from sugars. Appl Microbiol Biotechnol 45, 363-370. 
Lee, S.Y. and Choi, J.I. (1998) Effect of fermentation performance on the economics of poly(3-hydroxybutyrate) production by Alcaligenes latus. Polym Degrad Stab 59, $387-393$.

Madden, L.A., Anderson, A.J., Shah, D.T. and Asrar, J. (1999) Chain termination in polyhydroxyalkanoate synthesis: involvement of exogenous hydroxy-compounds as chain transfer agents. Int J Biol Macromol 25, 43-53.

Manaia, C.M. and Moore, E.R. (2002) Pseudomonas thermotolerans sp. nov., a thermotolerant species of the genus Pseudomonas sensu stricto. Int J Syst Evol Microbiol 52, 2203-2209.

McBain, J.W. and Sierichs, W.C. (1948) The solubility of sodium and potassium soaps and the phase diagrams of aqueous potassium soaps. J Am Oil Chem Soc 25, 221-225.

Oshima, T. and Imahori, K. (1974) Description of Thermus thermophilus (Yoshida and Oshima) comb. nov., a nonsporulating thermophilic bacterium from a Japanese thermal spa. Int J Syst Bacteriol 24, 102-112.

Pantazaki, A.A., Tambaka, M.G., Langlois, V., Guerin, P. and Kyriakidis, D.A. (2003) Polyhydroxyalkanoate (PHA) biosynthesis in Thermus thermophilus: purification and biochemical properties of PHA synthase. Mol Cell Biochem 254, 173-183.

Rehm, B.H.A., Krüger, N. and Steinbüchel, A. (1998) A new metabolic link between fatty acid de novo synthesis and polyhydroxyalkanoic acid synthesis. The PhaG gene from Pseudomonas putida KT2440 encodes a 3-hydroxyacyl-acyl carrier protein-coenzyme A 
transferase. J Biol Chem 273, 24044-24051.

Sivakumar, G., Vail, D.R., Xu, J.F., Burner, D.M., Lay, J.O., Ge, X.M. and Weathers, P.J. (2010) Bioethanol and biodiesel: Alternative liquid fuels for future generations. Eng Life Sci 10, 8-18.

Solaiman, D.K., Ashby, R.D. and Foglia, T.A. (2001) Production of polyhydroxyalkanoates from intact triacylglycerols by genetically engineered Pseudomonas. Appl Microbiol Biotechnol 56, 664-669.

Sudesh, K., Abe, H. and Doi, Y. (2000) Synthesis, structure and properties of polyhydroxyalkanoates: biological polyesters. Prog Polym Sci 25, 1503-1555.

Tamura, K, Dudley, J, Nei, M. and Kumar S (2007) MEGA4: Molecular Evolutionary Genetics Analysis (MEGA) software version 4.0. Mol Biol Evol 24, 1596-1599

Yazdani, S.S. and Gonzalez, R. (2007) Anaerobic fermentation of glycerol: a path to economic viability for the biofuels industry. Curr Opin Biotechnol 18, 213-219. 
Table 1 Monomer compositions of PHAs produced by strain SG4502

\begin{tabular}{|c|c|c|c|c|c|c|c|c|c|}
\hline \multirow[t]{2}{*}{$\begin{array}{l}\text { Carbon } \\
\text { Sources }\end{array}$} & \multirow{2}{*}{$\begin{array}{l}\text { Temp. } \\
\left({ }^{\circ} \mathrm{C}\right) \\
\end{array}$} & \multirow{2}{*}{$\begin{array}{l}\text { Total } \\
\text { Biomass }^{\mathrm{a}} \\
\left(\mathrm{g} \mathrm{l}^{-1}\right)\end{array}$} & \multirow{2}{*}{$\begin{array}{l}\text { PHA } \\
\text { yield } \\
\left(\mathrm{g} \mathrm{l}^{-1}\right)\end{array}$} & \multirow{2}{*}{$\begin{array}{l}\text { PHA } \\
\text { content } \\
(\%[w / w])\end{array}$} & \multicolumn{5}{|c|}{$\begin{array}{l}\text { Monomer composition } \\
(\mathrm{mol} \%)^{\mathrm{b}}\end{array}$} \\
\hline & & & & & $3 \mathrm{HB}$ & $3 \mathrm{HHx}$ & $3 \mathrm{HO}$ & $3 \mathrm{HD}$ & $3 \mathrm{HDD}$ \\
\hline BDF by-product & 45 & $1 \cdot 50$ & 0.61 & $40 \cdot 6$ & $0 \cdot 8$ & $5 \cdot 7$ & $25 \cdot 1$ & $59 \cdot 8$ & $8 \cdot 6$ \\
\hline Glycerol & 45 & 0.053 & $\operatorname{trace}^{\mathrm{c}}$ & - & 0 & 0 & 0 & 100 & 0 \\
\hline Acetate & 45 & $0 \cdot 57$ & $0 \cdot 06$ & $10 \cdot 1$ & $1 \cdot 0$ & $1 \cdot 4$ & $10 \cdot 4$ & $84 \cdot 4$ & $2 \cdot 9$ \\
\hline Octanoate & 45 & $1 \cdot 80$ & $0 \cdot 50$ & $28 \cdot 0$ & $0 \cdot 9$ & $10 \cdot 7$ & $82 \cdot 5$ & $5 \cdot 7$ & $0 \cdot 1$ \\
\hline \multirow[t]{2}{*}{ Dodecanoate } & 45 & $0 \cdot 30$ & $0 \cdot 11$ & $36 \cdot 1$ & $0 \cdot 7$ & $6 \cdot 3$ & $40 \cdot 2$ & $37 \cdot 8$ & $15 \cdot 0$ \\
\hline & 55 & $0 \cdot 41$ & $0 \cdot 10$ & $24 \cdot 0$ & 0 & $6 \cdot 0$ & $57 \cdot 0$ & $37 \cdot 0$ & 0 \\
\hline Soybean oil & 45 & $\operatorname{trace}^{\mathrm{c}}$ & - & - & - & - & - & - & - \\
\hline
\end{tabular}

${ }^{\text {a }}$ Total biomass was defined as cell components plus PHA.

b 3HB, 3-hydroxybutyrate (C4); 3HHx, 3-hydroxyhexanoate (C6); 3HO, 3-hydroxyoctanoate (C8); 3HD, 3-hydroxydecanoate (C10); 3HDD, 3-hydroxydodecanoate (C12).

${ }^{\mathrm{c}}$ Trace $<0.02 \mathrm{~g} / \mathrm{L}$ 
Table 2 Molecular weights of PHAs produced by strain SG4502

\begin{tabular}{llll}
\hline $\begin{array}{l}\text { Carbon } \\
\text { source }\end{array}$ & $\begin{array}{l}\text { Temp. } \\
\left({ }^{\circ} \mathrm{C}\right)\end{array}$ & $\begin{array}{l}\mathrm{Mn} \times 10^{-4} \\
\left(\mathrm{~g} \mathrm{~mol}^{-1}\right)\end{array}$ & $\mathrm{Mw} / \mathrm{Mn}$ \\
\hline $\begin{array}{l}\text { BDF by-product } \\
\text { Acetate }\end{array}$ & 45 & $3 \cdot 57$ & $1 \cdot 95$ \\
Octanoate & 45 & $7 \cdot 34$ & $2 \cdot 16$ \\
Dodecanoate & 45 & $10 \cdot 7$ & $2 \cdot 43$ \\
& 55 & $3 \cdot 67$ & $2 \cdot 21$ \\
\hline
\end{tabular}




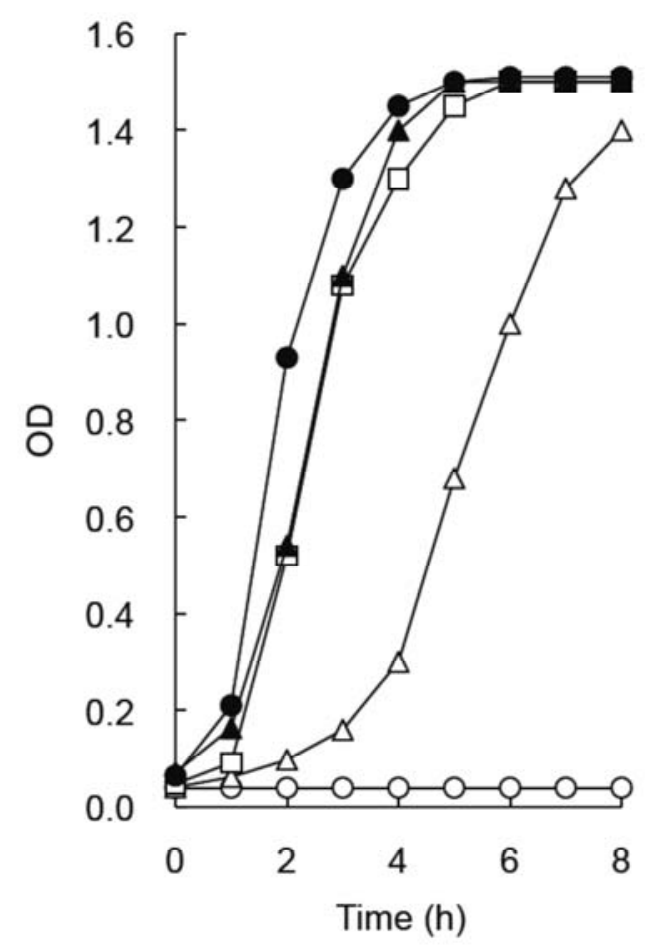

Figure 1 Growth curve of strain SG4502. The strain was cultured in NR medium at the indicated temperatures. Closed triangle, $37^{\circ} \mathrm{C}$; closed circle, $45^{\circ} \mathrm{C}$; open square, $50^{\circ} \mathrm{C}$; open triangle, $55^{\circ} \mathrm{C}$; open circle, $60^{\circ} \mathrm{C}$. 


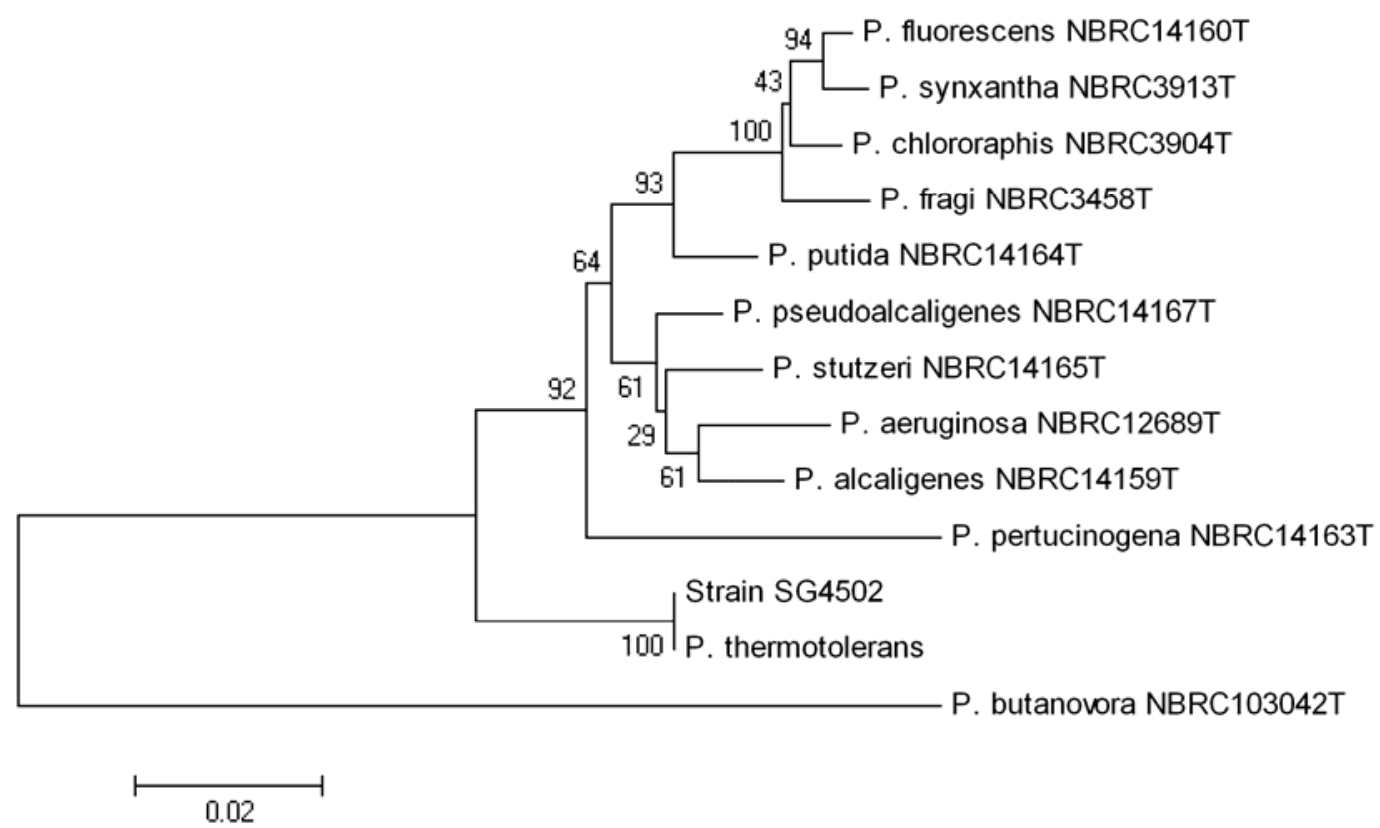

Figure 2 Phylogenetic tree of strain SG4502 and its related microorganisms. The 16S rRNA gene sequence of strain SG4502 was aligned with those of 11 type strains in Pseudomonas species collected at NITE Biological Resource Center (NBRC) as well as P. thermotolerans by using Molecular Evolutionary Genetics Analysis (MEGA) software version 4.0 (Tamura et al. 2007). A phylogenetic tree was constructed using the neighbor-joining method. The numbers on the tree indicate the percentages of bootstrap sampling, derived from 1000 replications. 


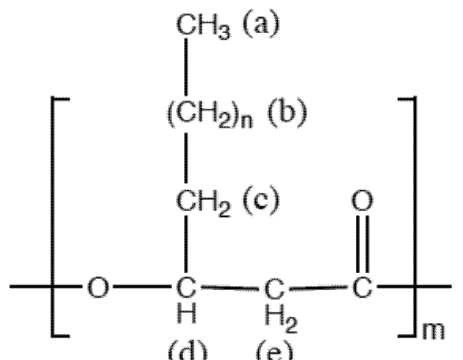

(b)

(a)

(c)

(d)

(e)

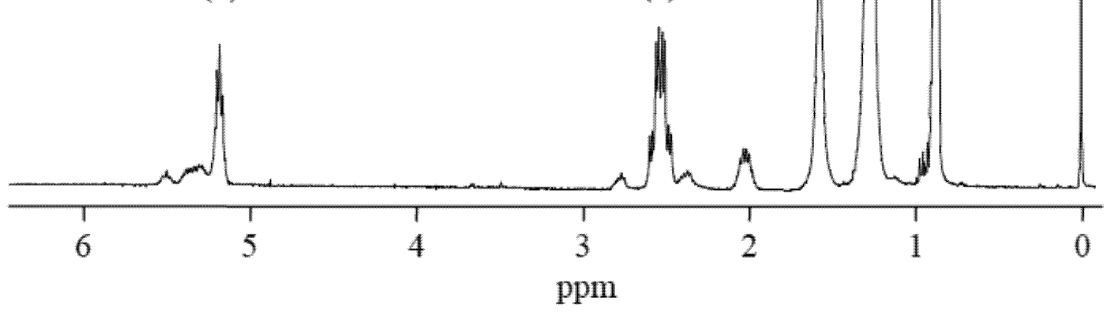

Figure $3{ }^{1} \mathrm{H}$ NMR spectrum of the polymer produced from BDF by-product. 